\title{
Removal of phenol from aqueous solution using carbonized Terminalia chebula-activated carbon: process parametric optimization using conventional method and Taguchi's experimental design, adsorption kinetic, equilibrium and thermodynamic study
}

\author{
Prateek Khare • Arvind Kumar
}

Received: 17 October 2011/ Accepted: 18 May 2012/Published online: 10 June 2012

(C) The Author(s) 2012. This article is published with open access at Springerlink.com

\begin{abstract}
In the present paper, the phenol removal from wastewater was investigated using agri-based adsorbent: Terminalia chebula-activated carbon (TCAC) produced by carbonization of Terminalia chebula (TC) in air-controlled atmosphere at $600{ }^{\circ} \mathrm{C}$ for $4 \mathrm{~h}$. The surface area of TCAC was measured as $364 \mathrm{~m}^{2} / \mathrm{g}$ using BET method. The surface characteristic of TCAC was analyzed based on the value of point of zero charge. The effect of parameters such as TCAC dosage, $\mathrm{pH}$, initial concentration of phenol, time of contact and temperature on the sorption of phenol by TCAC was investigated using conventional method and Taguchi experimental design. The total adsorption capacity of phenol was obtained as $36.77 \mathrm{mg} / \mathrm{g}$ using Langmuir model at the temperature of $30^{\circ} \mathrm{C}$ at $\mathrm{pH}=5.5$. The maximum removal of phenol $(294.86 \mathrm{mg} / \mathrm{g})$ was obtained using Taguchi's method. The equilibrium study of phenol on TCAC showed that experimental data fitted well to R-P model. The results also showed that kinetic data were followed more closely the pseudo-first-order model. The results of thermodynamic study showed that the adsorption of phenol on TCAC was spontaneous and an exothermic in nature.
\end{abstract}

Keywords Phenol - Adsorption - Point of zero charge · Pseudo first-order - Redlich and Peterson isotherm . Taguchi design $\cdot$ Orthogonal arrays $\cdot S / N$ ratio

P. Khare · A. Kumar $(\varangle)$

Department of Chemical Engineering,

National Institute of Technology, Rourkela 769008, Orissa, India

e-mail: arvindkumar@nitrkl.ac.in

\section{Introduction}

Phenolic pollutants are toxic in nature. Their presence can be commonly observed in the streams of various industrial wastewaters (Cao et al. 2003; Jiang et al. 2003). The presence of phenolic compounds represents a serious potential hazard for human health and aquatic life, and that is why phenols have been registered as a priority pollutant by the US Environmental Protection Agency (USEPA) with a permissible limit of $0.1 \mathrm{mg} / \mathrm{l}$ in wastewater (Srivastava et al. 2006; USEPA 1985). The Bureau of Indian Standards (BIS) and World Health Organization (WHO) recommend the permissible limit of phenol for drinking water as $1.0 \mu \mathrm{g} / 1$ (Srivastava et al. 2006; BIS 1974; IS 1983; Singh et al. 2008a, b). The MoEF has set a maximum concentration level of $1.0 \mathrm{mg} / \mathrm{l}$ of phenol in the industrial effluents for safe discharge into surface wastewater (Srivastava et al. 2006; Kamble et al. 2008; Kumar et al. 2011).

Therefore, the removal of phenols from industrial effluents is required before sewage disposal. For this purpose, various (more or less) environment-friendly methods have been suggested (Dursun et al. 2005; Liu et al. 2010; El-Naas et al. 2010). Several physicochemical and biological treatment techniques already exist today, but the most effective and frequently used procedure for phenol removal is adsorption on activated carbons (Dabrowski et al. 2005; Tong et al. 1998; Özkaya 2006; Girods et al. 2009).

Activated carbons to remove pollutants are currently produced from a variety of starting materials such as wastes and agricultural residues (Rio et al. 2005). Many researchers have shown that activated carbon is an effective adsorbent for organic compounds, especially for phenolic compounds. However, its high initial cost and the need for a costly regeneration system make it less economically viable 
as an adsorbent (Girods et al. 2009). Taking these criteria into consideration, the search for a low cost and easily available adsorbent has led many investigators to search more works (Dursun et al. 2005; Rio et al. 2005; Ozer and Tumen 2003; Altundogan 2005). The studies focusing on organic pollutants adsorption on TCAC and evaluating optimal process parameters conditions, kinetic, equilibrium and thermodynamic parameters are very limited.

There are multiples objectives of the present work such as to produce low-cost adsorbent from fruit's of TC plant for adsorption of phenol, characterization of prepared adsorbent for its valuables adsorption properties like BET surface area, CHNS analysis, and point of zero charge (PZC), and to investigate the effects of TCAC dosage $(w)$, initial phenol concentration $\left(C_{\mathrm{o}}\right)$, contact time $(t)$, temperature $(T)$ and $(\mathrm{pH})$, and establishing the optimal process parameters conditions for the optimal performance of the phenol-TCAC system using conventional method and Taguchi experimental design, to analyze the adsorption kinetics of phenol onto TCAC by pseudo first-order and pseudo second-order models, estimation of equilibrium isotherm constants and their fitness to experimental data using Langmuir, Freundlich and R-P isotherms equations and finally, to evaluate thermodynamic parameters to identify the nature of phenol adsorption.

\section{Methodology}

\section{Adsorbent and adsorbate}

The fruit's of TC plant having an elliptical shape, abrasive seed has enveloped by a fleshy and firm pulp were collected from plants of NIT Rourkela campus. The solidcoating part of the seed was used as a raw material for adsorbent preparation in the present work.

The solid-coating part of the seed was washed five to six times in running tap water and distilled water to remove impurities like ash. It was then soaked in $2 \mathrm{M} \mathrm{HCl}$ solutions for 2 days to increase the protonation in TCAC. The soaked material was sun dried and treated in pyrolysis reactor (figure not shown here) to produce char. The pyrolysis of raw material (TC) was carried out at heating rate $20{ }^{\circ} \mathrm{C} / \mathrm{min}$ and temperature $600{ }^{\circ} \mathrm{C}$ in the air-controlled atmosphere. The reaction was started at $436{ }^{\circ} \mathrm{C}$ and took 15-20 min to complete. The char was allowed to cool naturally in reactor. The char was crushed to a desired 100 BSS sieve size particle. The resultant char was then washed with double-distilled water (DDW) until the $\mathrm{pH}$ of washed water became neutral, and then, dried in oven to remove moisture for end use. Since this char granules were having the hardness and physical texture like activated carbon, hence named as Terminalia chebula-activated carbon.

The stock solution of phenol was prepared by dissolving $0.25 \mathrm{~g}$ of AR grade phenol in 1,000 ml of DDW. Batch adsorption experiments were performed after proper dilution of this stock solution.

\section{Batch experimental program}

For each experiment, phenol solution of known $C_{\mathrm{o}}$ and a known amount of the TCAC were taken in a $100 \mathrm{ml}$ airtight conical flask with a glass stopper. This mixture was agitated in a temperature-controlled shaking water bath at a constant shaking speed of $300 \mathrm{rpm}$. The $p$ removal $[R=$ $\left.100\left(C_{\mathrm{o}}-C_{t}\right) / C_{\mathrm{o}}\right]$ and phenol uptake $\left[q_{t}=\left(C_{\mathrm{o}}-C_{t}\right) \mathrm{V} / \mathrm{w}\right]$ by TCAC at any time $t$ were calculated. Where $C_{\mathrm{o}}$ is the initial phenol concentration $(\mathrm{mg} / \mathrm{l}), V$ the volume $(\mathrm{ml})$ of the wastewaters in the flask, $C_{t}$ the phenol concentration $(\mathrm{mg} / \mathrm{l})$ after time $t$ and $w$ is the mass of the TCAC $(\mathrm{g})$ used in the experiment. At equilibrium conditions, $q_{t}$ and $C_{t}$ are replaced by $q_{\mathrm{e}}$ and $C_{\mathrm{e}}$, respectively.

\section{Analytical measurements}

The standard calibration curve of known concentration of phenol was plotted using spectrophotometer by finding out the absorbance at the characteristic wavelength of $\lambda_{\text {max }}=270 \mathrm{~nm}$ (Vasu 2008) showing a linear variation up to $100 \mathrm{mg} / \mathrm{l}$ concentration. Therefore, the samples of higher concentration of phenol were subsequently diluted with DDW. The standard calibration curve of phenol concentration was used to find out the unknown concentration of phenol is various samples.

\section{Taguchi method}

Conventional and classical methods of studying a process by maintaining other factors involved at an unspecified constant level does not depict the combined effect of all the factors involved. This method is also time consuming and requires large number of experiments to determine optimum levels, which are unreliable (Elibol 2002; Ravikumar et al. 2006). Taguchi's parameter design is an important tool for robust design. It offers a simple and systematic approach to optimize design for performance, quality and cost. By applying this technique, one can significantly reduce the time required for experimental investigation, as it is effective in investigating the effects of multiple factors on performance as well as to study the influence of individual factors to determine which factor has more influence, which less (Ghani et al. 2004; Datta et al. 2008; Bendell 1988). 
Two major tools used in robust design are signal to noise $(S / N)$ ratio (Phadke 1989; Park 1996; Unal and Dean 1991; Ghani et al. 2004; Srivastava et al. 2007), which measures quality with emphasis on variation, and orthogonal arrays, which accommodate many design factors simultaneously.

\section{Orthogonal array experiments}

In this study, an orthogonal array $\left(\mathrm{L}_{25} \mathrm{OA}\right)$ with five columns and 25 rows was used. This array has 24 degrees of freedom and it can handle five-level design parameters. Each process variable is assigned to a column, 25 uptakeparameter combinations being available. Therefore, only 25 experiments are required to study the entire parameter space using the $\mathrm{L}_{25} \mathrm{OA}$. The experimental layout for the five uptake parameters using the $\mathrm{L}_{25} \mathrm{OA}$ is shown in Table 1.

\section{Adsorbent characterization}

The specific surface area of TCAC was measured via a nitrogen adsorption isotherm using an ASAP 2010 Micromeritics instrument and the data were analyzed using the Micromeritics software. The ultimate elemental analysis of laboratory-prepared TCAC sample was performed by a CHNS Thermo Finnigan Flash EATM 1112 analyzer. The zero surface charge characteristics of TCAC for phenol removal were determined using the solid addition method.

\section{Result and discussion}

\section{Adsorbent characterization}

The various properties of the TCAC produced from waste material of TC's fruits have been presented given in Table 2. The BET and Langmuir surface were estimated to be 364 and $413 \mathrm{~m}^{2} / \mathrm{g}$ respectively. CHNS analysis indicates that the activation was thus decreased the nitrogen content by typically lower than $1 \mathrm{wt}$. \%. Such an amount was lower than what can be found in N-enriched carbons (Vasu 2008). However, the present material is significantly cheaper in term of cost. In contrast, even if the resultant performances of phenol adsorption were expected to be lower.

Table 1 Experimental layout for using the $\mathrm{L}_{25} \mathrm{OA}$ and experimental result for phenol removal onto TCAC

\begin{tabular}{|c|c|c|c|c|c|c|c|c|c|}
\hline S. no & $T\left({ }^{\circ} \mathrm{C}\right)$ & $\mathrm{pH}$ & $w(\mathrm{~g})$ & $C_{\mathrm{o}}(\mathrm{mg} / \mathrm{l})$ & $t(\min )$ & $C_{t}(\mathrm{mg} / \mathrm{l})$ & $q_{\mathrm{e}}(\mathrm{mg} / \mathrm{g})$ & $S / N$ ratio & Mean \\
\hline 1 & 36 & 2 & 1 & 50 & 15 & 48.69 & 3.26 & 10.26 & 3.26 \\
\hline 2 & 36 & 4 & 2 & 100 & 30 & 85.98 & 17.52 & 24.87 & 17.52 \\
\hline 3 & 36 & 8 & 3 & 150 & 180 & 111.74 & 31.89 & 30.07 & 31.89 \\
\hline 4 & 36 & 10 & 4 & 200 & 840 & 92.30 & 67.31 & 36.56 & 67.31 \\
\hline 5 & 36 & 12 & 5 & 400 & 1,440 & 362.40 & 18.80 & 25.48 & 18.80 \\
\hline 6 & 41 & 2 & 2 & 150 & 840 & 56.86 & 116.43 & 41.32 & 116.43 \\
\hline 7 & 41 & 4 & 3 & 200 & 1,440 & 77.57 & 102.03 & 40.17 & 102.03 \\
\hline 8 & 41 & 8 & 4 & 400 & 15 & 392.00 & 5.00 & 13.97 & 5.00 \\
\hline 9 & 41 & 10 & 5 & 50 & 30 & 42.76 & 3.62 & 11.17 & 3.62 \\
\hline 10 & 41 & 12 & 1 & 100 & 180 & 91.23 & 21.93 & 26.82 & 21.93 \\
\hline 11 & 51 & 2 & 3 & 400 & 30 & 389.60 & 8.67 & 18.76 & 8.67 \\
\hline 12 & 51 & 4 & 4 & 50 & 180 & 42.87 & 4.46 & 12.98 & 4.46 \\
\hline 13 & 51 & 8 & 5 & 100 & 840 & 57.46 & 21.27 & 26.55 & 21.27 \\
\hline 14 & 51 & 10 & 1 & 150 & 1,440 & 32.06 & 294.86 & 49.39 & 294.86 \\
\hline 15 & 51 & 12 & 2 & 200 & 15 & 191.10 & 11.13 & 20.92 & 11.13 \\
\hline 16 & 56 & 2 & 4 & 100 & 1,440 & 85.92 & 8.80 & 18.88 & 8.80 \\
\hline 17 & 56 & 4 & 5 & 150 & 15 & 123.94 & 13.03 & 22.29 & 13.03 \\
\hline 18 & 56 & 8 & 1 & 200 & 30 & 123.94 & 190.16 & 45.58 & 190.16 \\
\hline 19 & 56 & 10 & 2 & 400 & 180 & 219.77 & 225.29 & 47.05 & 225.29 \\
\hline 20 & 56 & 12 & 3 & 50 & 840 & 32.06 & 14.95 & 23.49 & 14.95 \\
\hline 21 & 60 & 2 & 5 & 200 & 180 & 106.73 & 46.63 & 33.37 & 46.63 \\
\hline 22 & 60 & 4 & 1 & 400 & 840 & 398.00 & 5.00 & 13.97 & 5.00 \\
\hline 23 & 60 & 8 & 2 & 50 & 1,440 & 22.11 & 34.86 & 30.84 & 34.86 \\
\hline 24 & 60 & 10 & 3 & 100 & 15 & 99.13 & 0.72 & -2.85 & 0.72 \\
\hline 25 & 60 & 12 & 4 & 150 & 30 & 139.79 & 6.38 & 16.09 & 6.38 \\
\hline
\end{tabular}


Table 2 Different properties from CHNS analysis, EDX and BET surface area of TCAC

\begin{tabular}{lc}
\hline Analysis & Properties \\
\hline BET surface area Langmuir surface area $\left(\mathrm{m}^{2} / \mathrm{g}\right)$ & 364 \\
& 413 \\
Point of zero charge & 6.5 \\
\hline Elements & Weight percent \\
\hline EDX & \\
Carbon & 86.19 \\
Oxygen & 12.06 \\
Calcium & 1.74 \\
$C H N S$ & \\
Carbon & 82.86 \\
Hydrogen & 2.697 \\
Sulfur & 0.046 \\
Nitrogen & 0.55 \\
Oxygen & 13.847 \\
\hline
\end{tabular}

The PZC is an important property of carbon-water interfaces. The PZC is defined as the $\mathrm{pH}$ at which the carbon surface has no charge in the absence of specific adsorption. The carbon surface is positively charged at $\mathrm{pH}$ values below the $\mathrm{pH}_{\mathrm{PZC}}$ and negatively charged at $\mathrm{pH}$ values above the $\mathrm{pH}_{\mathrm{PZC}}$ (Álvarez-Merino et al. 2008). The limiting $\mathrm{pH}$ of solution is considered on the basis of $\mathrm{pH}_{\mathrm{PZC}}$ (Singh et al. 2008a, b). The experimental value of PZC of TCAC was estimated to be 6.5 (Table 2) using solid addition (Noh and Schwarz 1989).

\section{Taguchi experimental data analysis}

Taguchi uses the signal-to-noise $(S / N)$ ratio as the quality characteristic of choice (Phadke 1989; Park 1996; Kumar et al. 2008). $S / N$ Ratio is used as a measurable value instead of standard deviation due to the fact that as the mean decreases, the standard deviation also decreases and vice versa. Taguchi has empirically found that the two-stage optimization procedure involving $S / N$ ratios indeed gives the parameter level combination, where the standard deviation is minimum while keeping the mean on target
(Phadke 1989). The $S / N$ ratio characteristics can be divided into three categories when the characteristic is continuous:

Nominal is the best characteristic : $S / N=10 \log \left(\bar{y} / s_{y}^{2}\right)$

Smaller the better characteristics : $S / N$

$$
=-10 \log \frac{1}{n}\left(\sum y^{2}\right)
$$

and larger the better characteristics : $S / N$

$$
=-10 \log \frac{1}{n}\left(\sum \frac{1}{y^{2}}\right)
$$

where $\bar{y}$ is the average of observed data, $s_{y}^{2}$ the variance of $y, n$ the number of observations, and $y$ the observed data.

\section{Analysis of signal/noise ratio}

The Taguchi's experimental design results are transformed into a signal-to-noise $(S / N)$ ratio (Table 1) using Minitab software (version 13.2). Taguchi recommends the use of the $S / N$ ratio to measure the quality characteristics deviating from the desired values (Ghani et al. 2004; ElizaldeGonzalez and Hernandez-Montoya 2009). In the present work, the-higher-the-better $S / N$ ratio was selected as the category of quality characteristic. The mean $S / N$ ratio (Table 3 ) for each variable at each level was calculated by averaging the $S / N$ ratios for all the experiments. The optimal level of the process parameters was the level that corresponds to greatest $S / N$ ratio (Fig. 1). The max-min values of process variables are shown in Table 3 . Therefore, one can rank the influence the process variables for phenol removal onto TCAC (Table 3). Figure 1 shows the mean $S / N$ response graphs for the removal of the phenol. The results revealed that the optimal conditions for the removal of phenol are time at level $5(t=1,440 \mathrm{~min})$, phenol concentration at level $3\left(C_{\mathrm{o}}=150 \mathrm{mg} / \mathrm{l}\right)$, temperature at level $4\left(T=56^{\circ} \mathrm{C}\right), \mathrm{pH}$ at level $4(\mathrm{pH}=10)$ and adsorbent dosage at level $4(w=1 \mathrm{~g} / \mathrm{l})$. As shown in Table 3, these conditions exhibit the highest $S / N$ values $85.24,80.29,71.73,103.72$ and 84.65 for each factor and correspond to an unperformed experiment, where maximum removal of phenol $(294.86 \mathrm{mg} / \mathrm{g})$ was obtained.

\begin{tabular}{|c|c|c|c|c|c|c|c|c|}
\hline Symbol & Variables & 1 & 2 & 3 & 4 & 5 & $\begin{array}{l}\text { Maximum- } \\
\text { minimum }\end{array}$ & $\begin{array}{l}\text { Process } \\
\text { influencing rank }\end{array}$ \\
\hline$w$ & TCAC dosage (g) & 103.04 & 81.05 & 31.65 & 18.39 & 20.67 & 84.65 & 3 \\
\hline $\mathrm{pH}$ & Hydrogen ions strength & 36.76 & 28.41 & 56.64 & 118.60 & 14.64 & 103.72 & 1 \\
\hline$t$ & Time (min) & 6.63 & 45.27 & 66.04 & 45.00 & 91.87 & 85.24 & 2 \\
\hline$T$ & Temperature $\left({ }^{\circ} \mathrm{C}\right)$ & 27.56 & 49.80 & 68.80 & 90.45 & 18.72 & 71.73 & 5 \\
\hline$C_{\mathrm{o}}$ & Phenol concentration $(\mathrm{mg} / \mathrm{l})$ & 12.23 & 14.05 & 92.52 & 83.45 & 52.55 & 80.29 & 4 \\
\hline
\end{tabular}

Table 3 Response table for mean $S / N$ ratios for phenol-TCAC adsorption system 
Fig. 1 Mean $S / N$ ration graph for phenol adsorption onto TCAC

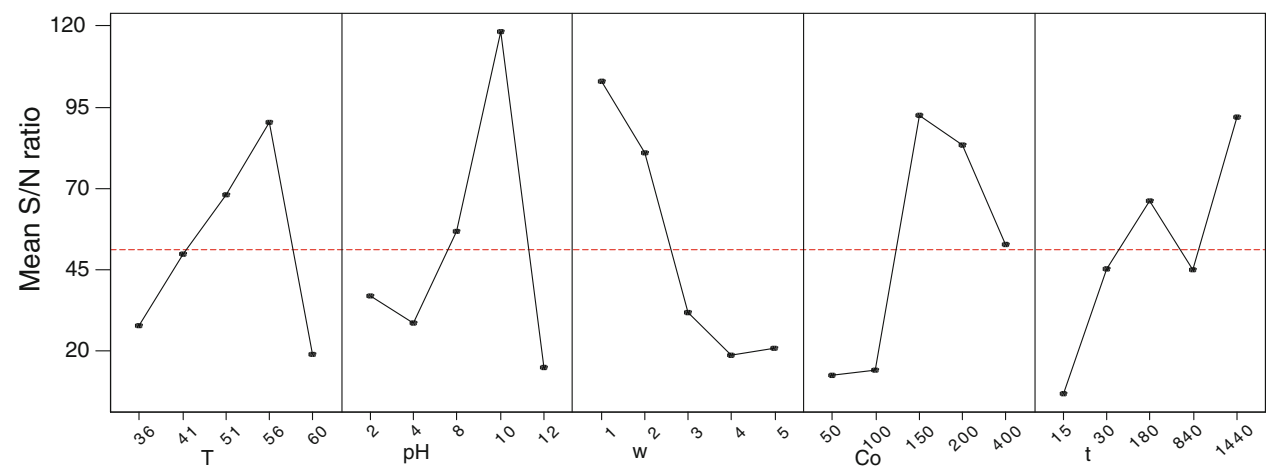

Effect of adsorbent dose

To study the effect of adsorbent dosage, the TCAC dosages were varied from 1 to $7 \mathrm{~g} / \mathrm{l}$ and placed into series of the $100 \mathrm{ml}$ conical flasks containing $100 \mathrm{mg} / \mathrm{l}$ phenol solutions. These samples were agitated for $24 \mathrm{~h}$ at $120 \mathrm{rpm}$ at the natural $\mathrm{pH}$. A plot of $q_{t}$ and percent removal was plotted on same axis against adsorbent dose (Fig. 2). It was found that with increase in adsorbent dose, the percent removal increases indicating the presence of large surface area available for phenol adsorption. Hence, the optimum dosage was considered where these graphs intersect each other, hence in all the experiments; $3 \mathrm{~g} / \mathrm{l}$ was kept as an optimum adsorbent dosage.

\section{Effect of initial $\mathrm{pH}$}

The very interesting result was obtained while elucidating the effect of $\mathrm{pH}$ for phenol removal onto TCAC. The uptake of phenol by the TCAC varies with $\mathrm{pH}$ as shown in Fig. 3. The surface properties (acidic and/or basic) of TCAC were influenced by the $\mathrm{pH}$ value of the adsorption medium. Phenol could be expected to dissociate according to Bronsted concept in different $\mathrm{pH}$ medium as follow:

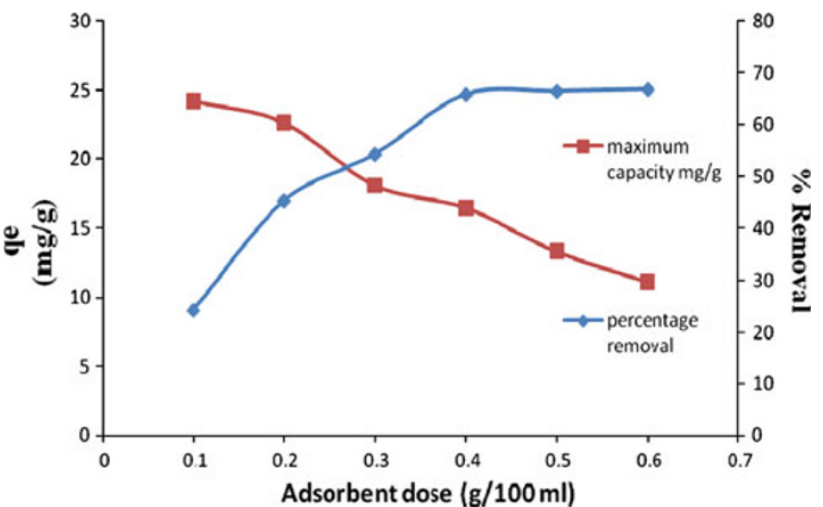

Fig. 2 Effect of TCAC dosage for phenol removal at $\mathrm{pH}=$ natural, $C_{\mathrm{o}}=100 \mathrm{mg} / \mathrm{l}, t=4 \mathrm{~h}, T=30{ }^{\circ} \mathrm{C}$

$$
\begin{aligned}
& \mathrm{HCl}+\mathrm{H}_{2} \mathrm{O} \leftrightarrow \underset{\text { hydronium ion }}{\mathrm{H}_{3} \mathrm{O}^{+}+\mathrm{Cl}^{-} \mathrm{C}_{5} \mathrm{H}_{5} \mathrm{OH}+\mathrm{H}_{2} \mathrm{O}} \\
& \leftrightarrow \mathrm{H}_{3} \mathrm{O}^{+}+\mathrm{C}_{6} \mathrm{H}_{5} \mathrm{O}^{-} \quad \text { Low pH medium } \\
& \text { phenolic ion } \\
& \mathrm{C}_{6} \mathrm{H}_{5} \mathrm{OH}+\underset{\text { hydronium ion }}{\mathrm{NaOH}}+\mathrm{H}_{2} \mathrm{O} \leftrightarrow \mathrm{H}_{3} \mathrm{O}^{+}+\mathrm{OH}^{-} \\
& +\mathrm{C}_{6} \mathrm{H}_{5} \mathrm{O}^{-} \mathrm{Na}^{+} \text {sod.phenolate High pH medium }
\end{aligned}
$$

At lower $\mathrm{pH}$ (acidic medium), phenol dissociate into $\mathrm{C}_{6} \mathrm{H}_{5} \mathrm{O}^{-}$and $\mathrm{H}_{3} \mathrm{O}^{+}$ions, while at higher $\mathrm{pH}$ (basic medium), it produces $\mathrm{C}_{6} \mathrm{H}_{5} \mathrm{O}^{-} \mathrm{Na}^{+}, \mathrm{H}_{3} \mathrm{O}^{+}$and $\mathrm{OH}^{-}$. It is clear evident from Fig. 3 that the uptake of phenol increases with the increase in $\mathrm{pH}$, and attain to the maximum value at $\mathrm{pH}=5.5$. Thereafter, the uptake of phenol decreases with increase in $\mathrm{pH}$ up to 8 indicating that the basic surface groups of TCAC were completely neutralized. Further, increase in $\mathrm{pH}$ causes again increase in phenol uptake showing the neutralization acidic surface groups present onto TCAC. The increase in uptake of phenol in acidic and basic medium can also be explained based on PZC, which is one of the important property to demonstrate the surface characteristic of the material in lower and higher $\mathrm{pH}$ medium (Dursun et al. 2005). It has been shown that the PZC decreases with increases in temperature (Álvarez-

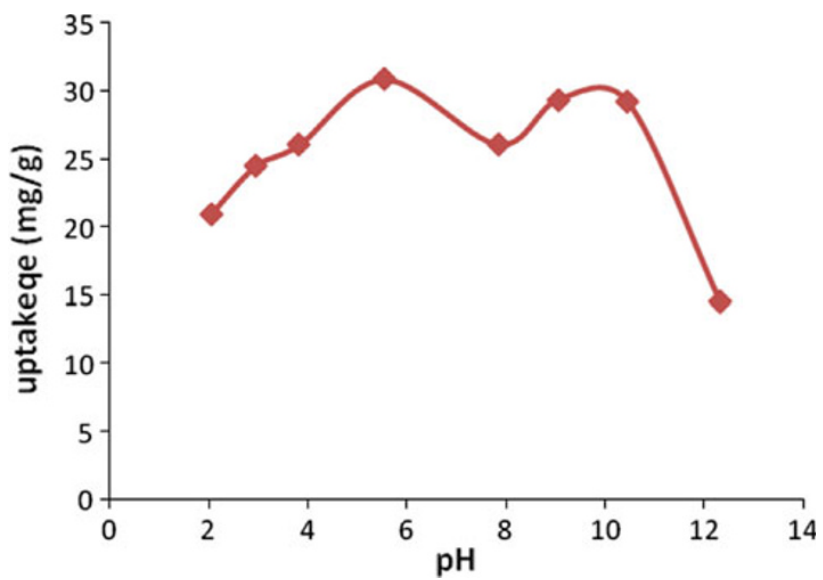

Fig. 3 Effect of $\mathrm{pH}$ for phenol removal onto TCAC at $t=24 \mathrm{~h}$, $C_{\mathrm{o}}=100 \mathrm{mg} / \mathrm{l}, T=30^{\circ} \mathrm{C}$ 
Merino et al. 2008). The $\mathrm{pH}$ at which the surface charge is zero, is called the PZC. The surface is positively charged at $\mathrm{pH}<\mathrm{pH}_{\mathrm{PZC}}$ and negatively charged at $\mathrm{pH}>\mathrm{pH}_{\mathrm{PZC}}$ (Liu et al. 2010; Dabrowski et al. 2005; Álvarez-Merino et al. 2008). The degree of ionization of phenol is also $\mathrm{pH}$ dependent (Kennedy et al. 2007). In this study, the amount of phenol adsorbed found to be highest at $\mathrm{pH}=5.5$ followed by at $\mathrm{pH}=10$. At $\mathrm{pH}=5.5$ (final $\mathrm{pH}$ $5.5<6.5 \mathrm{pH}_{\mathrm{PZC}}$ ), so the surface of TCAC is positively charged as a consequences, there is weak electrostatic attraction exhibits between the phenolic ion $\left(\mathrm{C}_{6} \mathrm{H}_{5} \mathrm{O}^{-}\right)$and the positively charged surface of TCAC. Thus, the adsorption is favored as the $\mathrm{pH}$ raises up to 5.5. But at $\mathrm{pH}=10$ (final $\mathrm{pH} 10>6.5 \mathrm{pH}_{\mathrm{PZC}}$ ), the carbon surface becomes negatively charged resulting in increased adsorption due to the attraction between the polar sodium phenolate and negative charge of the TCAC surface. However, the uptake of sodium phenolate (polar molecule) was mild at higher $\mathrm{pH}$ as compare to phenolic ion at lower $\mathrm{pH}$.

The electrostatic attraction at $5.5<\mathrm{pH}_{\mathrm{PZC}}<10$, a significant adsorption of phenol onto TCAC takes place indicating that physical adsorption might be involved in the present study, This was later on confirmed by the estimation of thermodynamics parameters of the phenol-TCAC system.

\section{Effect of contact time and initial phenol concentration}

To elucidate the effect of initial concentration of phenol $\left(C_{\mathrm{o}}=100 \mathrm{mg} / \mathrm{l}\right)$, the batch experiments were carried out in series of conical flasks with constant TCAC dosage of $w=3 \mathrm{~g} / \mathrm{l}$ in all the samples. These flasks were agitated in water bath shaker for 15, 30, 60, 210, 720 and 1,440 min keeping $\mathrm{pH}=5.5$ fixed in all the samples. The samples were withdrawn from the water bath shaker at predetermined time intervals. The phenol solution was separated out from the adsorbent filtering with $0.45 \mu \mathrm{m}$ Whatman Millipore filter. The concentration of phenol in supernatant was measured for all the samples. The $q_{\mathrm{e}}$ was evaluated for all the samples and a graph was plotted between $q_{\mathrm{e}}$ versus $t$ as shown in Fig. 4. The adsorption data for the uptake of phenol versus contact time at different initial concentrations is presented in this paper; the results showed that equilibrium time required for the adsorption of phenol onto TCAC was $1,440 \mathrm{~min}(24 \mathrm{~h})$. However, the results also indicated that up to $50 \%$ of the total amount of phenol uptake was found to occur in the first $30 \mathrm{~min}$, and thereafter, the rest $50 \%$ of maximum uptake was reached in $24 \mathrm{~h}$. The uptake capacity increased with increase in $C_{\mathrm{o}}$, which may be due to the availability of more number of phenolate ion in solution for sorption. Moreover, higher $C_{\mathrm{o}}$ provided higher driving force to overcome all mass transfer resistances of the phenolate ions from the aqueous to the

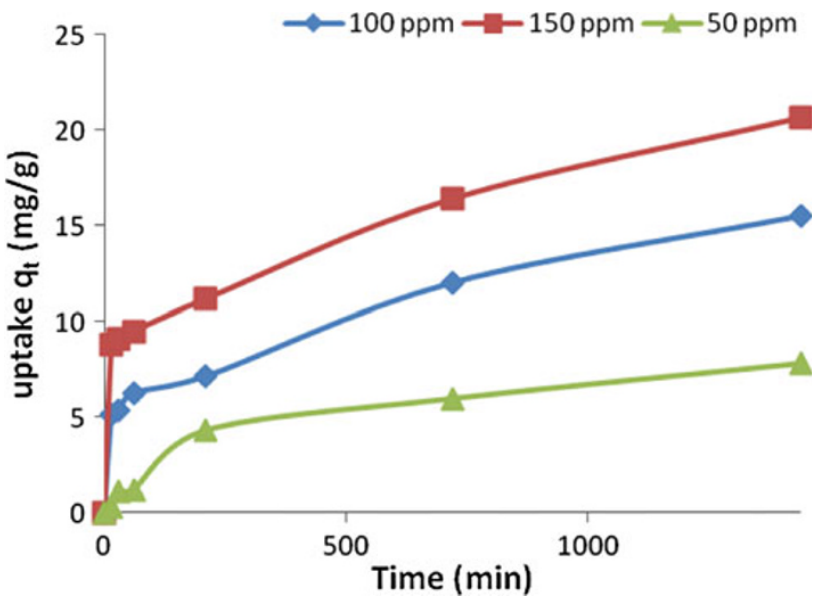

Fig. 4 Effect of contact time and initial concentrations of phenol on the adsorption of phenol onto TCAC at $w=3 \mathrm{~g} / \mathrm{l}, T=30^{\circ} \mathrm{C}$, $\mathrm{pH}=5.5$

solid phase resulting in higher probability of collision between adsorbent and the active sites of adsorbent (Srivastava et al. 2006). The higher sorption rate at the initial period (first $30 \mathrm{~min}$ ) may be due to an availability of large number of vacant sites on the adsorbent at the initial stage, as a result, there was an increase in concentration gradients between adsorbate in solution and adsorbate on adsorbent surface. Thus, there was a tendency to increase in phenol sorption at the initial stages. As time precedes this concentration is reduced due to the accumulation of phenol particles in the vacant sites leading to a decrease in the sorption rate at the larger stages from 30 to 1,440 min. It is also seen that an increase in $C_{\mathrm{o}}$ resulted in increased phenol uptake.

\section{Effect of temperature}

For the analysis of surface loading with increase in temperature, the phenol solutions of different concentration $\left(C_{\mathrm{o}}=50,100,150,200,250 \mathrm{mg} / \mathrm{l}\right)$ were prepared in five conical flasks. In each sample, $3 \mathrm{~g} / 1$ TCAC dose was added, and these samples were placed and agitated for $24 \mathrm{~h}$ in water bath shaker for different temperature in the varying range of $30-60{ }^{\circ} \mathrm{C}$. The final phenol concentration was measured after $24 \mathrm{~h}$ for each sample. A plot of $q_{\mathrm{e}}$ versus $C_{\mathrm{e}}$ was plotted for different temperatures (Fig. 5) The equilibrium uptake of phenol molecules onto TCAC decreased with increase in temperature from 30 to $60{ }^{\circ} \mathrm{C}$ indicating less chemical interaction between the sorbate and the surface functionalities of the active carbons. Phenol adsorption was exothermic and thus the extent of adsorption decreased with increase in temperature (Ravikumar et al. 2006; Kennedy et al. 2007; Kumar et al. 2008; Wang and Chu 2011). 


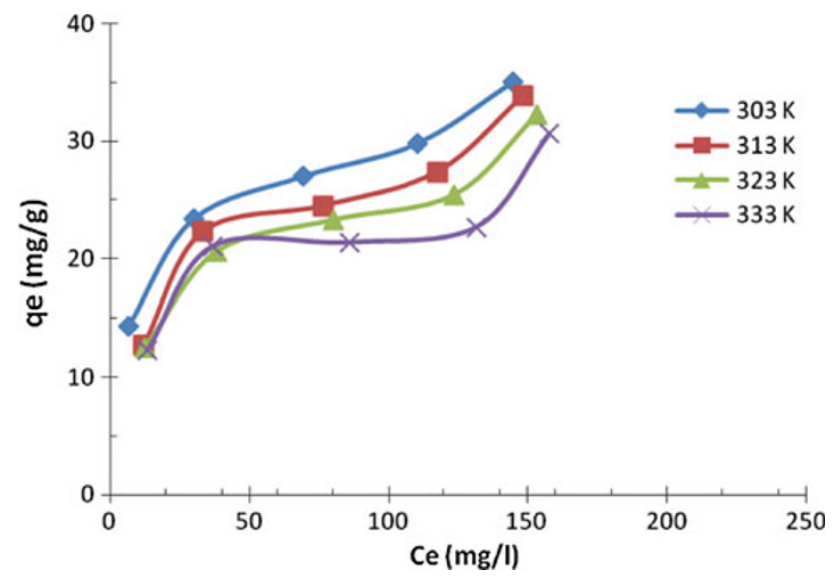

Fig. 5 Effect of surface loading of TCAC with temperature at $w=3 \mathrm{~g} / \mathrm{l}, \mathrm{pH}=5.5, t=24 \mathrm{~h}$

\section{Adsorption kinetics and isotherms study}

The kinetics was fitted to the pseudo first-order, pseudo second-order, intraparticle diffusion models and Bangam model. The pseudo second-order, intraparticle diffusion models and Bangam model gives poor fitting with low $R^{2}$ values. The pseudo first-order model fits the experimental data quite well for phenol-TCAC adsorption system (Fig. 6), the $R^{2}$ values are close to unity and there are variances in the experimental and theoretical uptakes. The values of the rate constants for pseudo first-order kinetic models are shown in Table 4.

To optimize the design of an adsorption system for the adsorption of the pollutants, it is important to establish the most appropriate correlation for the equilibrium curves. Various isotherm equations have been used to describe the equilibrium nature of adsorption. An adsorption isotherm is characterized by certain constant values, which express the
Table 4 Kinetic parameters at $30{ }^{\circ} \mathrm{C}$ and isotherm parameters at $C_{\mathrm{o}}=50-250 \mathrm{mg} / \mathrm{l}, w=3 \mathrm{~g} / \mathrm{l}$ and $t=24 \mathrm{~h}$ for the removal of phenol on TCAC

\begin{tabular}{|c|c|c|c|c|}
\hline Equation $\downarrow C_{\mathrm{o}} \rightarrow$ & $50(\mathrm{mg} / \mathrm{l})$ & \multicolumn{2}{|c|}{$100(\mathrm{mg} / \mathrm{l})$} & $50(\mathrm{mg} / \mathrm{l})$ \\
\hline \multicolumn{5}{|c|}{ Pseudo first-order equation: $\log \left(q_{\mathrm{eq}}-q\right)=\log q_{\mathrm{eq}}-\frac{k_{\mathrm{f}}}{2.303} t$} \\
\hline$k_{\mathrm{f}}\left(\min ^{-1}\right)$ & 0.0115 & 0.0023 & \multicolumn{2}{|c|}{0.0023} \\
\hline$q_{\mathrm{e}, \exp }(\mathrm{mg} / \mathrm{g})$ & 11.35 & 26.23 & \multicolumn{2}{|c|}{16.41} \\
\hline$q_{\mathrm{e}, \mathrm{cal}}(\mathrm{mg} / \mathrm{g})$ & 8.38 & 20.24 & \multicolumn{2}{|c|}{9.80} \\
\hline$R^{2}$ & 0.9822 & 0.9810 & \multicolumn{2}{|c|}{0.9960} \\
\hline Isotherm constants $\downarrow$ & $\rightarrow \quad 30\left({ }^{\circ} \mathrm{C}\right)$ & $40\left({ }^{\circ} \mathrm{C}\right)$ & $50\left({ }^{\circ} \mathrm{C}\right)$ & $60\left({ }^{\circ} \mathrm{C}\right)$ \\
\hline \multicolumn{5}{|c|}{ Langmuir isotherm: $q_{\mathrm{e}}=q_{\mathrm{m}} K_{\mathrm{L}} C_{\mathrm{e}} /\left(1+K_{\mathrm{L}} C_{\mathrm{e}}\right)$} \\
\hline$K_{\mathrm{L}}(1 / \mathrm{mg})$ & 0.0581 & 0.0376 & 0.0345 & 0.0409 \\
\hline$q_{\mathrm{m}}(\mathrm{mg} / \mathrm{g})$ & 36.77 & 36.57 & 34.70 & 30.77 \\
\hline$R^{2}$ & 0.9894 & 0.9795 & 0.9746 & 0.9586 \\
\hline \multicolumn{5}{|c|}{ Freundlich isotherm: $q_{\mathrm{e}}=K_{\mathrm{F}} C_{\mathrm{e}}^{1 / n}$} \\
\hline$K_{\mathrm{F}}(\mathrm{mg} / \mathrm{g}) /(\mathrm{mg} / \mathrm{l})^{1 / t}$ & 8.6380 & 5.8310 & 5.4611 & 6.1092 \\
\hline $1 / n$ & 0.2743 & 0.3416 & 0.3386 & 0.2926 \\
\hline$R^{2}$ & 0.9905 & 0.9649 & 0.9746 & 0.9182 \\
\hline \multicolumn{5}{|c|}{ R-P isotherm: $q_{\mathrm{e}}=K_{\mathrm{R}} C_{\mathrm{e}} /\left(1+a_{\mathrm{R}} C_{\mathrm{e}}^{\beta}\right)$} \\
\hline$K_{\mathrm{R}}(1 / \mathrm{mg})$ & 15.931 & 4.861 & 35.31 & 4.826 \\
\hline$a_{\mathrm{R}}$ & 2.0860 & 0.5346 & 6.1473 & 0.5328 \\
\hline$\beta$ & 0.7580 & 0.7410 & 0.6706 & 0.7760 \\
\hline$R^{2}$ & 0.9989 & 0.9920 & 0.9933 & 0.9958 \\
\hline
\end{tabular}

surface properties and affinity of the adsorbent and can also be used to compare the adsorptive capacities of the adsorbent. Large number of researchers in the field of environmental engineering have used Freundlich and Langmuir isotherm equations to represent equilibrium adsorption data for different kinds of adsorption systems, despite the fact that these equations have serious limitations on their usage (Langmuir 1916; Freundlich 1906).
Fig. 6 Pseudo first-order kinetic plot for the PhenolTCAC system at $w=3 \mathrm{~g} / \mathrm{l}$, $\mathrm{pH}=5.5$

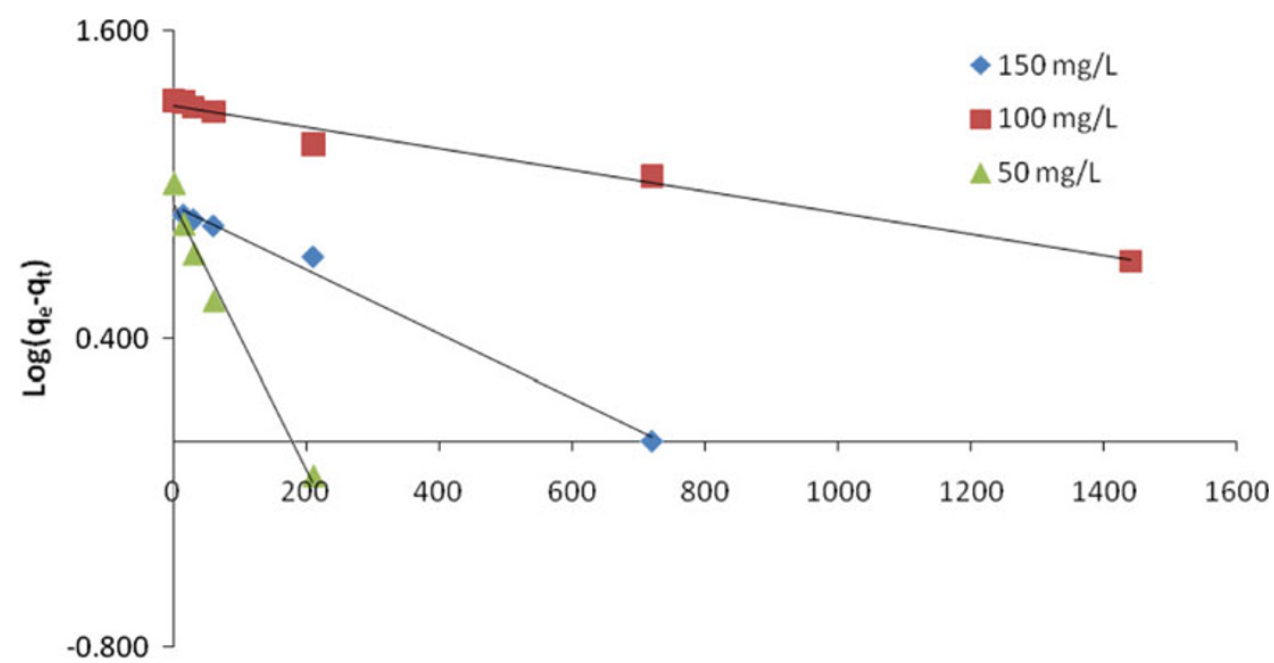

Time (minute) 
The Redlich and Peterson (R-P) equation is a three parameter equation, often used to represent solute adsorption data on heterogeneous surfaces. This equation reduces to Freundlich equation at high concentrations.

In this study, the adsorption equilibrium of phenol on TCAC was modeled using Langmuir, Freundlich and, Redlich and Peterson (R-P) isotherms. Their constants and $R^{2}$ values were obtained (Table 4) from the plots of $q_{\mathrm{e}}$ versus $C_{\mathrm{e}}$ at $30{ }^{\circ} \mathrm{C}$ as presented in Fig. 5. As seen from the table 4, comparison of $R^{2}$ values for various isotherms for phenol-TCAC adsorption systems shows that these values are closer to unity for R-P indicating its fitness to adsorption data. The magnitude of $K_{\mathrm{F}}$ and $1 / n$ of the Freundlich isotherm constants showed the tendency of phenol uptake from the adsorption medium with high capacity of the TCAC (Girods et al. 2009). The highest $K_{\mathrm{F}}$ value was determined as 8.64 at this temperature. All $1 / n<1$ indicates that phenol was favorably adsorbed by TCAC at all temperatures studied (Shi et al. 2010). Both the $q_{\max }$ and $K_{\mathrm{L}}$ values determined from Langmuir equation decreased from 36.77 to $30.77 \mathrm{mg} / \mathrm{g}$ and from 0.058 to 0.040 with increasing temperature from 30 to $60{ }^{\circ} \mathrm{C}$, respectively. The maximum capacity, $q_{\max }$ defines the total capacity of the TCAC for phenol. The other Langmuir constant, $K_{\mathrm{L}}$ indicates the affinity for the binding of phenol. The higher value of $K_{\mathrm{L}}$ found at $30{ }^{\circ} \mathrm{C}$ showed strong bonding of phenol to the TCAC.

Determination of thermodynamic parameters

The thermodynamics study was performed to know the feasibility of the process. Parameters including Gibbs free energy change $\left(\Delta G^{\circ}\right)$, enthalpy change $\left(\Delta H^{\circ}\right)$ and entropy change $\left(\Delta S^{\mathrm{o}}\right)$ was estimated by applying Van't Hoff equation, and equilibrium constant was calculated using (Liu et al. 2010).

$\Delta G^{\mathrm{o}}=-R T \ln K_{\mathrm{ad}}$

$\Delta G^{\mathrm{o}}=\Delta H^{\mathrm{o}}-T \Delta S^{\mathrm{o}}$

$\ln K_{\mathrm{ad}}=-\Delta H^{\mathrm{o}} / R T+\Delta S^{\mathrm{o}} / R$

where $K_{\text {ad }}(1 / \mathrm{mol})$ is from Langmuir equation, $R$ is the gas constant $(8.314 \mathrm{~J} / \mathrm{mol} \mathrm{K})$ and $T$ is the temperature in

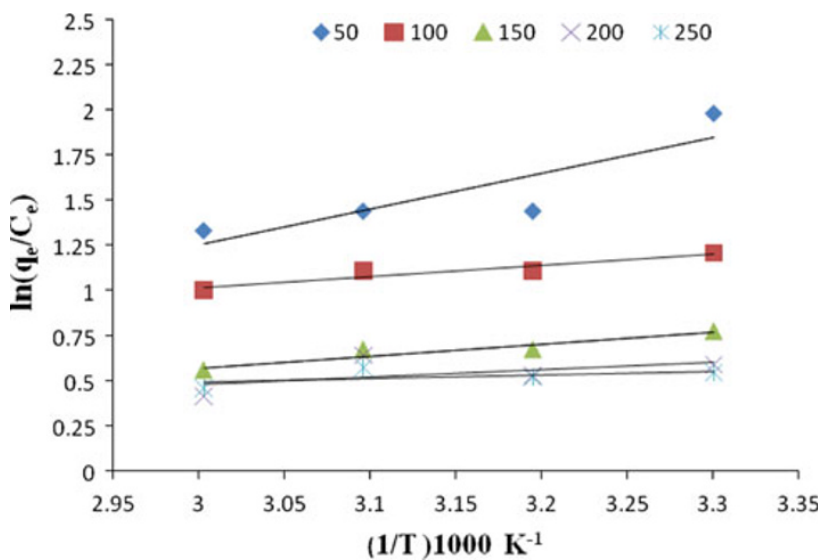

Fig. 7 The effect of temperature on the equilibrium distribution coefficient for phenol at $w=3 \mathrm{~g} / \mathrm{l}, \mathrm{pH}=5.5, t=24 \mathrm{~h}$

Kelvin. In the application of Eq. (3), the values of $\ln K_{\text {ad }}$ are plotted (Fig. 7) against $1 / T$ and, the $\Delta H^{\circ}$ (in $\mathrm{J} / \mathrm{mol}$ ) and $\Delta S^{\circ}$ (in $\mathrm{J} / \mathrm{mol} \mathrm{K}$ ) values are calculated from the slope and intercept of the plot.

The thermodynamic parameters are listed in Table 5. Negative $\Delta G^{\circ}$ values were obtained in all cases, revealing the spontaneous and exothermic in nature of phenol adsorption onto TCAC (Srivastava et al. 2006; Dursun et al. 2005; Huang et al. 2008). The $\Delta H^{\mathrm{o}}$ values were negative demonstrating the exothermic nature of adsorption (El-Naas et al. 2010; Senturk et al. 2009), which is in agreement with the experimental observations. The positive values of $\Delta S^{\circ}$ show the increased randomness of the solid-solution interface during the sorption of phenol on TCAC. These positive values of entropy may be due to some structural changes in both adsorbates and adsorbents during the adsorption process (Alkaram et al. 2009; Li et al. 2005).

\section{Conclusion}

The results indicated that adsorption capacity of the TCAC was considerably affected by adsorbent dosage, initial $\mathrm{pH}$, temperature and initial phenol concentration. The large

Table 5 Thermodynamic parameters for the adsorption of phenols

\begin{tabular}{|c|c|c|c|c|c|c|}
\hline Concentration & $T(\mathrm{~K})$ & $50(\mathrm{mg} / \mathrm{l})$ & $100(\mathrm{mg} / \mathrm{l})$ & $150(\mathrm{mg} / \mathrm{l})$ & $200(\mathrm{mg} / \mathrm{l})$ & $250(\mathrm{mg} / \mathrm{l})$ \\
\hline$\Delta H^{\mathrm{o}}(\mathrm{J} / \mathrm{mol})$ & & -16.60 & -5.11 & -5.48 & -3.41 & -1.68 \\
\hline$\Delta S^{\mathrm{o}}(\mathrm{J} / \mathrm{mol} . \mathrm{K})$ & & 5.32 & 3.73 & 1.71 & 0.87 & 0.17 \\
\hline \multirow[t]{4}{*}{$\Delta G^{\mathrm{o}}(\mathrm{J} / \mathrm{mol})$} & 303 & $-1,626.09$ & $-1,133.68$ & -521.15 & -266.40 & -51.05 \\
\hline & 313 & $-1,679.21$ & $-1,170.93$ & -538.17 & -275.08 & -52.68 \\
\hline & 323 & $-1,732.32$ & $-1,208.18$ & -555.19 & -283.76 & -54.31 \\
\hline & 333 & $-1,785.44$ & $-1,245.42$ & -572.20 & -292.44 & -55.94 \\
\hline
\end{tabular}


Table 6 Comparison of optimal process parameters for maximum removal efficiency

\begin{tabular}{lll}
\hline Processes parameters and result & $\begin{array}{l}\text { Conventional } \\
\text { method }\end{array}$ & $\begin{array}{l}\text { Taguchi } \\
\text { method }\end{array}$ \\
\hline$w: T$ CAC dosage $(\mathrm{g} / \mathrm{l})$ & 3 & 1 \\
$t:$ contact time $(\mathrm{min})$ to achieve equilibrium & 1,440 & 1,440 \\
$\mathrm{pH}:$ hydrogen ion strength & 5.5 & 10 \\
$C_{\mathrm{o}}:$ initial phenol concentration $(\mathrm{mg} / \mathrm{l})$ & 100 & 150 \\
$T:$ temperature $\left({ }^{\circ} \mathrm{C}\right)$ & 30 & 56 \\
$q_{\mathrm{e}}:$ uptake of phenol $(\mathrm{mg} / \mathrm{g})$ & 26.22 & 294.86 \\
$q_{\text {max }}:$ total uptake capacity of phenol $(\mathrm{mg} / \mathrm{g})$ & 36.77 & - \\
\hline
\end{tabular}

variation in phenol uptake by convectional and Taguchi method occurs due to the factors interaction involvement in Taguchi method (Table 6).

The kinetic, equilibrium and thermodynamic parameters for the adsorption of phenol onto TCAC was also determined. The negative value of $\Delta G^{\mathrm{o}}$ confirms the spontaneous nature adsorption process. The positive value of $\Delta S^{\circ}$ shows the increased randomness at the solid-solution interface during adsorption and the negative value of $\Delta H^{\circ}$ indicates that adsorption process is exothermic in nature (Table 5).

The various kinetic models were used to analyze data obtained for phenol adsorption onto TCAC. The results indicated that the pseudo first-order equation provided the better correlation for the adsorption data and the equilibrium data were well described by the R-P model (Table 4).

It can be concluded that the carbonized product from fruit's of Terminalia chebula (TC) plant is an efficient adsorbent for the removal of phenol from aqueous solution in both the medium (acidic and/or basic).

Acknowledgments The authors highly thank the Director of NIT Rourkela for providing financial assistance to the first author during the course of the work.

Open Access This article is distributed under the terms of the Creative Commons Attribution License which permits any use, distribution, and reproduction in any medium, provided the original author(s) and the source are credited.

\section{References}

Alkaram UF, Mukhlis AA, Al-Dujaili AH (2009) The removal of phenol from aqueous solutions by adsorption using surfactantmodified bentonite and kaolinite. J Hazard Mater 169:324-332

Altundogan HS (2005) Cr(VI) removal from aqueous solution by iron (III) hydroxide-loaded sugar beet pulp. Process Biochem 40:1443-1452

Álvarez-Merino MA, Fontecha-Cámara MA, López-Ramón MV, Moreno-Castilla C (2008) Temperature dependence of the point of zero charge of oxidized and non-oxidized activated carbons. Carbon 46(5):778-787
Bendell T (1988) Taguchi methods. In: Proceedings of the 1988 European conference on Taguchi method. Elsevier, Amsterdam, 13-14 July, 1988

Bureau of Indian Standards (BIS) (1974) Tolerance limit for industrial effluents discharged into inland surface waters: Coke Oven. IS 2490 (part 1). BIS, New Delhi

Cao S, Chen G, Hu X, Yue PL (2003) Catalytic wet air oxidation of wastewater containing ammonia and phenol over activated carbon supported Pt catalysts. Catal Today 88:37-47

Dabrowski A, Podkoscielny P, Hubicki Z, Barczak M (2005) Adsorption of phenolic compounds by activated carbon: a critical review. Chemosphere 58:1049-1070

Datta S, Bandyopadhyay A, Pal PK (2008) Slag recycling in submerged arc welding and its influence on weld quality leading to parametric optimization. Int J Adv Manuf Technol 39:229-238

Dursun G, Cicek H, Dursun AY (2005) Adsorption of phenol from aqueous solution by using carbonized beet pulp. J Hazard Mater B $125: 175-180$

Elibol M (2002) Response surface methodological approach for inclusion of per fluorocarbon in actinorhodin fermentation medium. Process Biochem 38:667-773

Elizalde-Gonzalez MP, Hernandez-Montoya V (2009) Removal of acid orange 7 by guava seed carbon: a four parameter optimization study. J Hazard Mater 168:515-522

El-Naas MH, Al-Zuhair S, Manal AA (2010) Removal of phenol from petroleum refinery wastewater through adsorption on date-pit activated carbon. Chem Engg J 162:997-1005

Freundlich HMF (1906) Over the adsorption in solution. J Phys Chem $57: 385-471$

Ghani JA, Choudhury IA, Hassan HH (2004) Application of Taguchi method in the optimization of end milling parameters. J Mater Process Tech 145:84-92

Girods P, Dufour A, Fierro V, Rogaume Y, Rogaumea C, Zoulalian A, Celzard A (2009) Activated carbons prepared from wood particleboard wastes: characterization and phenol adsorption capacities. J Hazard Mater 166:491-501

Huang Y, Ma X, Liang G, Yan H (2008) Adsorption of phenol with modified rectorite from aqueous solution. Chem Engg J 141:1-8

IS (1983) Indian Standards Specification for Drinking Water. Annexures VII and VIII, IS 10500

Jiang H, Fang Y, Fu Y, Guo QX (2003) Studies on the extraction of phenol in wastewater. J Hazard Mater B 101:179-190

Kamble SP, Mangrulkar PA, Bansiwal AK, Rayalu SS (2008) Adsorption of phenol and o-chlorophenol on surface altered fly ash based molecular sieves. Chem Eng J 138:73-83

Kennedy LJ, Vijaya JJ, Kayalvizhi K, Sekaran G (2007) Adsorption of phenol from aqueous solutions using mesoporous carbon prepared by two-stage process. Chem Engg J 132:279-287

Kumar A, Prasad B, Mishra IM (2008) Optimization of process parameters for acrylonitrile removal by a low-cost adsorbent using Box-Behnken design. J Hazard Mater 150:174-182

Kumar S, Zafar M, Prajapati JK, Kumar S, Kannepalli S (2011) Modeling studies on simultaneous adsorption of phenol and resorcinol onto granular activated carbon from simulated aqueous solution. J Hazard Mater 185:287-294

Langmuir I (1916) The constitution and fundamental properties of solids and liquids. J Am Chem Soc 38(11):2221-2295

Li YH, Di Z, Ding J, Wu D, Luan Z, Zhu Y (2005) Adsorption thermodynamic, kinetic and desorption studies of $\mathrm{Pb}^{2+}$ on carbon nanotubes. Water Res 39:605-609

Liu Q-S, Zheng T, Wang P, Ji-P Jiang, Li N (2010) Adsorption isotherm, kinetic and mechanism studies of some substituted phenols on activated carbon fibers. Chem Engg J 157:348-356

Noh JS, Schwarz JA (1989) Estimation of the point of zero charge of simple oxides by mass titration. J Colloid Interface Sci 130:157-164

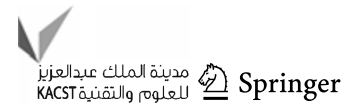


Ozer A, Tumen F (2003) Cd (II) adsorption from aqueous solution by activated carbon from sugar beet pulp impregnated with phosphoric acid. Fresenius Environ Bull 12:1050-1058

Özkaya B (2006) Adsorption and desorption of phenol on activated carbon and a comparison of isotherm models. J Hazard Mater B 129:158-163

Park SH (1996) Robust design and analysis for quality engineering. Chapman and Hall, London

Phadke MS (1989) Quality engineering using robust design. PrenticeHall, Englewood Cliffs

Ravikumar K, Ramalingam S, Krishnan S, Balu K (2006) Application of response surface methodology to optimize the process variables for reactive red and acid brown dye removal using a novel adsorbent. Dyes Pigm 70:18-26

Rio S, Faur-Brasquet C, Coq LL, Courcoux P, Cloirec PL (2005) Experimental design methodology for the preparation of carbonaceous sorbents from sewage sludge by chemical activation: application to air and water treatments. Chemosphere 58:423437

Senturk HB, Ozdes D, Gundogdua A, Duran C, Soylak M (2009) Removal of phenol from aqueous solutions by adsorption onto organomodified Tirebolu bentonite: equilibrium, kinetic and thermodynamic study. J Hazard Mater 172:353-362

Shi Q, Zhang J, Zhang C, Li C, Zhang B, Hu W, Xu J, Zhao R (2010) Preparation of activated carbon from cattail and its application for dyes removal. J Environ Sci 22(1):91-97

Singh KP, Malik A, Sinha S, Ojha P (2008a) Liquid-phase adsorption of phenols using activated carbons derived from agricultural waste material. J Hazard Mater 150:626-641
Singh RK, Kumar S, Kumar S, Kumar A (2008b) Development of parthenium based activated carbon and its utilization for adsorptive removal of p-cresol from aqueous solution. J Hazard Mater 155:523-535

Srivastava VC, Swamy MS, Mall ID, Prasad B, Mishra IM (2006) Adsorptive removal of phenol by bagasse fly ash and activated carbon: equilibrium, kinetics and thermodynamics. Colloid Surf A 272:89-104

Srivastava VC, Mall ID, Mishra IM (2007) Multicomponent adsorption study of metal ions onto bagasse fly ash using Taguchi's design of experimental methodology. Ind Eng Chem Res 46(17):5697-5706

Tong Z, Qingxiang Z, Hui H, Qin L, Yi Z, Min Q (1998) Kinetic study on the removal of toxic phenol and chlorophenol from waste water by horseradish peroxidase. Chemosphere 37:15711577

Unal R, Dean EB (1991) Taguchi approach to design optimization for quality and cost: an overview. In: Proceedings of the international society of parametric analyst $13^{\text {th }}$ annual, May 21-24, 1991

United States Environmental Protection Agency (USEPA) (1985) Technical support document for water quality based toxics control: EPA/440/485032. USEPA, Washington, DC

Vasu AE (2008) Removal of phenol and o-cresol by adsorption onto activated carbon. E J Chem 5(2):224-232

Wang Y, Chu W (2011) Adsorption and removal of a xanthene dye from aqueous solution using two solid wastes as adsorbents. Ind Eng Chem Res 50:8734-8741 